\title{
Xylanibacter oryzae gen. nov., sp. nov., a novel strictly anaerobic, Gram-negative, xylanolytic bacterium isolated from rice-plant residue in flooded rice-field soil in Japan
}

\author{
Atsuko Ueki, Hiroshi Akasaka,† Daisuke Suzuki, Satoshi Hattori \\ and Katsuji Ueki \\ Faculty of Agriculture, Yamagata University, Wakaba-machi 1-23, Tsuruoka 997-8555, Japan
}

Correspondence

Atsuko Ueki

uatsuko@tds1.tr.yamagata-u.ac.jp
As the principal food crop, rice is widely cultivated in Japan using irrigated fields. Diverse fermentative bacterial groups play a key role in the decomposition of organic matter in anoxic rice-field soil during the flooding period. Plant residues such as rice straw, stubble and roots ploughed into the soil are utilized by bacteria and methanogenic substrates such as acetate, formate and $\mathrm{H}_{2}$ are produced. The methane produced from these substrates is released into the atmosphere as one of the major greenhouse gases (Takai, 1970; Seiler et al., 1984; Boone, 2000; Khalil, 2000; Wassmann et al., 2000a, b).

tPresent address: Creative Research Initiative 'Sousei' (CRIS), Hokkaido University, Kita 21, Nishi 10, Kita-ku, Sapporo, 001-0021, Japan.

Abbreviations: CFA, whole-cell fatty acid; CMC, carboxymethylcellulose. The GenBank/EMBL/DDBJ accession number for the 16S rRNA gene sequence of strain $\mathrm{KB}^{\top}$ is $\mathrm{AB} 078826$.
During the course of an investigation into microbes in anoxic rice-field soil, we have isolated various fermentative anaerobes from samples of rice-plant residue, as well as living rice roots, in irrigated rice-field soil (Satoh et al., 2002; Akasaka et al., 2003a, 2004). We have previously described two novel anaerobic, propionate-producing species that were isolated from rice straw samples (Akasaka et al., 2003b; Ueki et al., 2006). In this study, a novel strain, $\mathrm{KB}^{\mathrm{T}}$, one of a group of isolates from stubble and roots that were phylogenetically distant from any related recognized species, was characterized. The novel isolate was a strictly anaerobic, xylanolytic and propionate-producing bacterium consisting of Gram-negative, non-motile rod-like cells. Based on phylogenetic, ecological, physiological and chemotaxonomic characteristics, we propose a novel genus and species in the phylum Bacteroidetes to accommodate strain $\mathrm{KB}^{\mathrm{T}}$.

Strain $\mathrm{KB} 3^{\mathrm{T}}$ was isolated from a sample of rice-plant residue (rice stubble and roots) collected from irrigated rice-field soil at the Shonai Branch of the Yamagata Agricultural 
Experimental Station (Tsuruoka, Yamagata, Japan) during the flooding period of the field. Cultivation practices for rice plants and other conditions of the fields have been described previously (Ueki et al., 2000). The strain was isolated by the anaerobic roll tube method for the enumeration of anaerobic fermentative bacteria by the colony-counting method (Hungate, 1966; Holdeman et al., 1977). Plant residue samples (rice stubble and roots) homogenized using a Waring blender (10 000 r.p.m., 10 min) under $\mathrm{N}_{2}$ gas were used as sources for the isolation of novel strains (Akasaka et al., 2003a, 2004).

The novel strain was cultivated anaerobically at $30^{\circ} \mathrm{C}$ unless otherwise stated. Peptone-yeast extract (PY) medium was used as the basal medium with oxygen-free, $95 \% \mathrm{~N}_{2} / 5 \%$ $\mathrm{CO}_{2}$ mixed gas as the headspace as described by Akasaka et al. (2003a). PY medium supplemented with $\left(\mathrm{l}^{-1}\right) 0 \cdot 25 \mathrm{~g}$ glucose, cellobiose, maltose and soluble starch and $15 \mathrm{~g}$ agar (Difco) was designated PY4S agar and used for the maintenance of the novel strain in agar slants. For the cultivation of the strain for various physiological tests and chemotaxonomic analyses, PYHV medium [PY liquid medium supplemented with haemin (at a final concentration of $5 \mathrm{mg} \mathrm{l}^{-1}$; Holdeman et al., 1977) and B-vitamin mixture $\left(10 \mathrm{ml} \mathrm{l}^{-1}\right)$ ] and PYHVG medium (PYHV medium supplemented with $10 \mathrm{~g}$ glucose $1^{-1}$ ) were used, unless otherwise stated. Since strain $\mathrm{KB}^{\mathrm{T}}$ was slightly acidophilic, as described below, the $\mathrm{pH}$ of liquid media was usually adjusted to about $\mathrm{pH} 6 \cdot 0$. The composition of the $\mathrm{B}$ vitamin mixture used was $\left(100 \mathrm{ml}^{-1}\right) 0 \cdot 1 \mathrm{mg}$ biotin, $0 \cdot 1 \mathrm{mg}$ cyanocobalamin (vitamin $\mathrm{B}_{12}$ ), $0.3 \mathrm{mg}$-aminobenzoic acid, $0.5 \mathrm{mg}$ folic acid, $0.5 \mathrm{mg}$ thiamine hydrochloride, $0.5 \mathrm{mg}$ riboflavin and $1.5 \mathrm{mg}$ pyridoxine hydrochloride (Akasaka et al., 2004). Growth in liquid medium was monitored by changes in $\mathrm{OD}_{660}$.

Growth of the novel strain under aerobic conditions was examined by plate culture on nutrient agar (Nissui Pharmacy) and PY4S agar modified to exclude $\mathrm{Na}_{2} \mathrm{CO}_{3}$, cysteine- $\mathrm{HCl}-\mathrm{H}_{2} \mathrm{O}$ and sodium resazurine in PY basal medium. Spore formation was assessed by observation of cells after Gram-staining and by growth of cells exposed to $80^{\circ} \mathrm{C}$ for $10 \mathrm{~min}$. Oxidase, catalase and nitrate-reducing activities were determined according to methods described by Satoh et al. (2002) and Akasaka et al. (2003a, b). Utilization of carbon sources was tested in PYHV liquid medium with each substrate added at a concentration of $10 \mathrm{~g} \mathrm{l}^{-1}$ (for sugars and sugar alcohols) or $30 \mathrm{mM}$ (organic acids). Bile sensitivity was determined by the addition of bile salts (Oxoid; $0 \cdot 1-0 \cdot 5 \%, \mathrm{w} / \mathrm{v}$ ) to PYHVG and PYG media (Lawson et al., 2002). Fermentation products were analysed by GC or HPLC as described previously (Ueki et al., 1986; Akasaka et al., 2003a). Other characterizations were performed according to the methods described by Holdeman et al. (1977) and Ueki et al. (2006).

Whole-cell fatty acids (CFAs) were converted to methyl esters according to the method of Miller (1982). Methyl esters of CFAs were analysed by GC (HP6890; Hewlett
Packard or G-3000; Hitachi) equipped with a HP Ultra2 column. CFAs were identified by equivalent chain-length (ECL) (Miyagawa et al., 1979; Ueki \& Suto, 1979) according to Moore's protocol of NCIMB Japan based on the MIDI microbial identification system (Microbial ID) (Moore et al., 1994). The microbial identification system of the TSBA40 was also used for confirmation of identification. Isoprenoid quinones were extracted as described by Komagata \& Suzuki (1987) and analysed by using a mass spectrometer (JMSSX102A; JEOL). Genomic DNA was extracted according to the method of Kamagata \& Mikami (1991). Extracted DNA was digested with P1 nuclease by using a Yamasa GC kit (Yamasa shoyu) and the DNA G $+\mathrm{C}$ content was measured by HPLC (L-7400; Hitachi) equipped with a $\mu$ Bondpack C18 column $(3 \cdot 9 \times 300 \mathrm{~mm}$; Waters $)$.

DNA extraction and PCR amplification were performed according to the method described by Akasaka et al. (2003a). The PCR-amplified 16S rRNA gene was sequenced by using a Thermo Sequenase Primer Cycle sequencing kit (Amersham Biosciences) and a DNA sequencer (4000L; LiCOR). Multiple alignments of the sequence with reference sequences in GenBank were performed with the BLAST program (Altschul et al., 1997). A phylogenetic tree was constructed with the neighbour-joining method (Saitou \& Nei, 1987) by using CLUSTAL W (Thompson et al., 1994). All gaps and unidentified base positions in the alignments were excluded before sequence assembly.

Cells of strain $\mathrm{KB}^{\mathrm{T}}$ were Gram-negative rods. The strain grew very slowly in PYG liquid medium without haemin. The addition of haemin to the medium greatly enhanced growth as described below and the morphology of the cells was significantly altered depending on the growth medium. Most of the cells grown in the presence of haemin were short rods $(0 \cdot 6-0 \cdot 7 \times 2 \cdot 2-2 \cdot 6 \mu \mathrm{m})$ with some longer rods $(4-10 \mu \mathrm{m})$ (Fig. 1a), while cells grown on PY4S agar slants (without haemin) often occurred as filamentous rods (20-50 $\mu \mathrm{m}$ long) with some chains of cells (Fig. 1b). Cells were non-motile as observed by phase-contrast microscopy. Colonies on PY4S agar were translucent and thin with a smooth surface and were $0 \cdot 5-0.8 \mathrm{~mm}$ diameter after 3-4 days of incubation. The novel strain could not grow in air either on PY4S or nutrient agar. Spore formation was not observed and cells treated at $80^{\circ} \mathrm{C}$ for $10 \mathrm{~min}$ did not grow.

The specific growth rate $(\mu)$ of strain $\mathrm{KB}^{\mathrm{T}}$ in PYG liquid medium (without haemin) was very low at $0.015 \mathrm{~h}^{-1}$ at $30^{\circ} \mathrm{C}$. In the presence of haemin $\left(5 \mathrm{mg} \mathrm{l}^{-1}\right.$; PYHG medium), the strain grew very rapidly with a growth rate of $0 \cdot 29-0 \cdot 33 \mathrm{~h}^{-1}$. Haemin at a lower concentration $\left(0.5 \mathrm{mg} \mathrm{l}^{-1}\right)$ also supported rapid growth. Addition of the B-vitamin mixture (PYHVG medium) did not apparently affect the growth rate, but the fermentation products of the strain were changed, as described below. Vitamin $\mathrm{K}$ did not affect the growth or fermentation of the novel strain. 

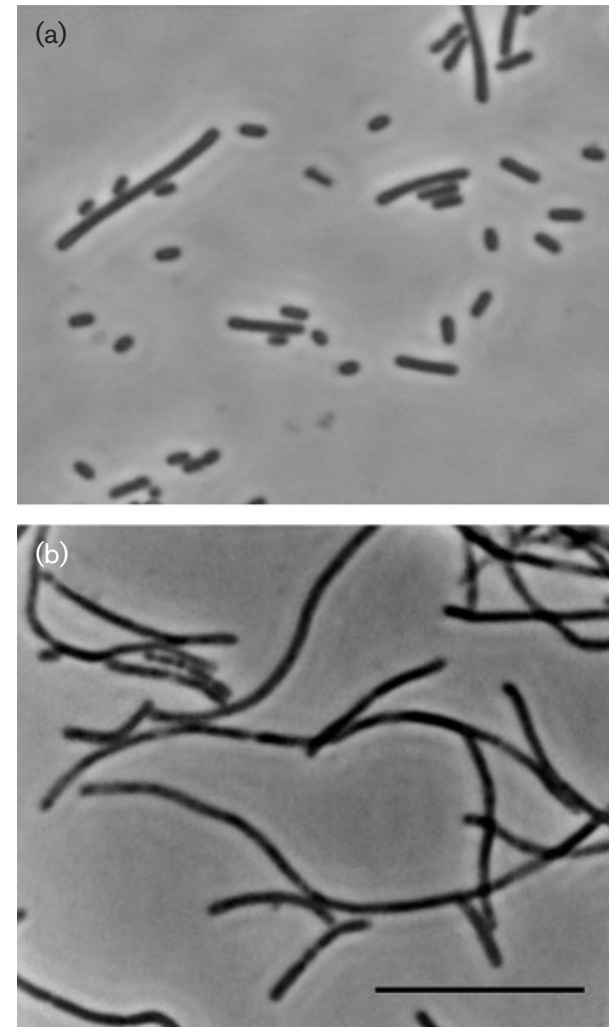

Fig. 1. Phase-contrast photomicrographs of cells of strain $\mathrm{KB}^{\top}$ grown anaerobically in PYG liquid medium with both haemin and the B-vitamin mixture (a) or on an agar slant of PY4S medium without haemin or the B-vitamin mixture (b). Bar, $10 \mu \mathrm{m}$.

When cells were cultivated to the stationary growth phase in the presence of haemin and then used as an inoculum for growth experiments, the growth of the strain was often found to be considerably delayed, irrespective of the haemin concentration of the medium. Thus, the viability or culturability of the cells grown in the presence of haemin appeared to be significantly reduced early in the stationary phase. Thus, for stable and reproducible growth experiments, it was essential to use cells in the late-exponential or early-stationary growth phase. Cells cultivated without haemin did not show any significant decline of viability, even at the stationary phase. Thus, PY4S agar, a medium without haemin, was usually used for the maintenance of the novel strain as slant cultures.

Both catalase and oxidase activities were negative and the novel strain did not reduce nitrate. Strain $\mathrm{KB}^{\mathrm{T}}$ utilized arabinose, ribose, xylose, fructose, galactose, glucose, mannose, rhamnose, cellobiose, lactose, maltose, sucrose, trehalose, carboxymethylcellulose (CMC), soluble starch, xylan, pectin, salicin and pyruvate as growth substrates. Acids were produced from all substrates used, but gas was not. Strain $\mathrm{KB}^{\mathrm{T}}{ }^{\mathrm{did}}$ not use sorbose, melezitose, cellulose powder, filter paper, inulin, glycerol, inositol, mannitol, fumarate, lactate, malate or succinate.

The major products of the novel strain in PYHG medium were acetate and succinate. Propionate production was significantly stimulated in the presence of the B-vitamin mixture (Table 1). Strain $\mathrm{KB}^{\mathrm{T}}$ also produced substantial amounts of acetate, propionate and succinate from xylan and, with this substrate, propionate production was also significantly stimulated by the addition of the B-vitamin mixture. The B-vitamin mixture could be completely replaced by cyanocobalamin at the same concentration as in the vitamin mixture (final concentration of $10 \mu \mathrm{g} \mathrm{l}^{-1}$ ). Propionate was also a major product from pectin, CMC and pyruvate in the presence of the vitamin mixture, while succinate was a minor product. A small amount of malate was usually detected. Formate was not detected from any of the substrates examined.

Aesculin was hydrolysed, but gelatin was not. Production of urease, hydrogen sulfide and indole were negative. The novel strain could not grow in the presence of $0.1 \%(\mathrm{w} / \mathrm{v})$ bile salts, irrespective of the presence or absence of haemin, demonstrating that the strain was sensitive to bile salts.

Strain $\mathrm{KB}^{\mathrm{T}}$ was slightly acidophilic with the optimum $\mathrm{pH}$ at $5 \cdot 7-6 \cdot 2$ and a $\mathrm{pH}$ range of $4 \cdot 7-7 \cdot 3$ for growth. Even at an initial $\mathrm{pH}$ of $7 \cdot 3$, growth was significantly delayed. When the novel strain was grown in PYHVG medium at an initial $\mathrm{pH}$ of $6 \cdot 1$, the final $\mathrm{pH}$ was $4 \cdot 1$. The temperature range for growth was $10-37^{\circ} \mathrm{C}$, with an optimum temperature of $30^{\circ} \mathrm{C}$. The growth rate at $37^{\circ} \mathrm{C}\left(\mu=0 \cdot 194 \mathrm{~h}^{-1}\right)$ was significantly lower than that at $30^{\circ} \mathrm{C}\left(0 \cdot 29-0.33 \mathrm{~h}^{-1}\right)$ and the strain could not grow at $37^{\circ} \mathrm{C}$ in the absence of haemin. The $\mathrm{NaCl}$ concentration range for growth was $0-0.5 \%(\mathrm{w} / \mathrm{v})$.

Table 1. Fermentation products of strain $\mathrm{KB}^{\top}$ from different substrates with or without vitamin in PY medium supplemented with haemin

Concentration of substrates: pyruvate, $30 \mathrm{mM}$, others, $1 \%(\mathrm{w} / \mathrm{v})$. +, With B-vitamin mixture; -, without B-vitamin mixture; tr, trace; ND, not detected.

\begin{tabular}{|lccccc|}
\hline \multirow{2}{*}{ Substrate } & Vitamin & \multicolumn{4}{c|}{ Fatty acid $\left(\mathbf{m m o l ~ l}^{\mathbf{- 1}}\right)$} \\
\cline { 2 - 6 } & & Acetate & Propionate & Succinate & Malate \\
\hline \multirow{2}{*}{ Glucose } & - & $6 \cdot 1$ & $0 \cdot 3$ & $14 \cdot 1$ & $0 \cdot 2$ \\
& + & $9 \cdot 4$ & $6 \cdot 1$ & $15 \cdot 7$ & $0 \cdot 3$ \\
Xylan & - & $7 \cdot 4$ & $3 \cdot 4$ & $8 \cdot 3$ & tr \\
& + & $9 \cdot 2$ & $12 \cdot 4$ & $4 \cdot 4$ & $0 \cdot 1$ \\
& $+*$ & $7 \cdot 2$ & $10 \cdot 9$ & $3 \cdot 8$ & $0 \cdot 1$ \\
Pectin & + & $3 \cdot 3$ & $8 \cdot 6$ & $0 \cdot 1$ & $\mathrm{ND}$ \\
CMC & + & $2 \cdot 4$ & $11 \cdot 4$ & $0 \cdot 6$ & $\mathrm{ND}$ \\
Pyruvate & + & $15 \cdot 1$ & $11 \cdot 8$ & $0 \cdot 5$ & $0 \cdot 1$ \\
& & & & & \\
\hline
\end{tabular}

${ }^{\star}$ Cyanocobalamin $\left(10 \mu \mathrm{g} \mathrm{l}^{-1}\right)$ in place of B-vitamin mixture. 
The major CFAs of strain $\mathrm{KB}^{\mathrm{T}}{ }^{\mathrm{T}}$ were anteiso- $\mathrm{C}_{15: 0}(42 \cdot 2 \%)$ and iso-3-OH C $\mathrm{C}_{17: 0}(21 \cdot 8 \%)$, with lower amounts of $3-\mathrm{OH}$ $\mathrm{C}_{17: 0}(5 \cdot 2 \%), \mathrm{C}_{15: 0}(4 \cdot 7 \%)$, anteiso-3-OH $\mathrm{C}_{17: 0}(3 \cdot 7 \%)$, iso- $\mathrm{C}_{15: 0}(3 \cdot 7 \%)$, iso- $\mathrm{C}_{17: 0}(3 \cdot 3 \%)$ and $\mathrm{C}_{16: 0}(3 \cdot 1 \%)$. Unsaturated fatty acids were not detected. The predominant respiratory quinones of the strain were menaquinones MK$12\left(\mathrm{H}_{2}\right)$ and $\mathrm{MK}-13\left(\mathrm{H}_{2}\right)$. The $\mathrm{G}+\mathrm{C}$ content of genomic DNA was $43 \cdot 6 \mathrm{~mol} \%$.

Strain $\mathrm{KB}^{\mathrm{T}}$ was assigned to the phylum Bacteroidetes (Garrity \& Holt, 2001) based on the 16S rRNA gene sequence (Fig. 2). The closest recognized species to strain $\mathrm{KB}^{\mathrm{T}}$ was Prevotella bivia ATCC $29303^{\mathrm{T}}$ (originally described as Bacteroides bivius) (Holdeman \& Johnson, 1977; Holdeman et al., 1984 ) with a gene sequence similarity of $89 \cdot 5 \%$. Prevotella albensis DSM $11370^{\mathrm{T}}$ (formerly Bacteroides ruminicola subsp. ruminicola biovar 7) (Holdeman et al., 1984; Avgustin et al., 1997) and Prevotella oulorum ATCC $43324^{\mathrm{T}}$ (Shah et al., 1985 ) were the next most closely related species (both with gene sequence similarity of $89 \cdot 1 \%$ ). The fourth and fifth most closely related species were also species of the genus Prevotella (Prevotella corporis and Prevotella loescheii, with 88.8 and $88.7 \%$ gene sequence similarity, respectively) (Holdeman et al., 1984). The species found to be most closely related to strain $\mathrm{KB}^{\mathrm{T}}$ are all isolates from mammalian species, including the urogenital region of humans (P. bivia), rumen (P. albensis), oral cavities of humans ( $P$. oulorum and $P$. loescheii) and other human clinical specimens ( $P$. corporis) (Holdeman et al., 1984; Shah et al., 1985).

Some characteristics of strain $\mathrm{KB}^{\mathrm{T}}$ and the three most closely related species are compared in Table 2 . Phylogenetic analysis revealed that strain $\mathrm{KB}^{\mathrm{T}}$ showed $16 \mathrm{~S}$ rRNA gene sequence similarity values of less than $90 \%$ with the closest recognized species. The genus Prevotella mainly consists of species from human oral or urogenital sources with important exceptions isolated from rumen, such as $P$. ruminicola, $P$. albensis, Prevotella brevis and Prevotella bryantii (Shah \& Collins, 1989, 1990; Paster et al., 1994; Avgustin et al., 1997). Strain $\mathrm{KB}^{\mathrm{T}}{ }^{\mathrm{T}}$ was isolated from a very different environment, rice-plant residue from anoxic rice-field soil, from the known habitats of the recognized Prevotella species. The optimum growth temperature of strain $\mathrm{KB}^{\mathrm{T}}$ at $30^{\circ} \mathrm{C}$ may reflect the different environmental source of this strain compared with other related species. In addition to the low 16S rRNA gene sequence similarity values, the obvious ecological difference strongly indicates that strain $\mathrm{KB}^{\mathrm{T}}$ represents a novel taxon in the phylum Bacteroidetes that inhabits anaerobic environments other than mammals.

Many species of the genus Prevotella have a requirement for haemin for growth. The closest relatives of strain $\mathrm{KB}^{\mathrm{T}}, P$. bivia, $P$. albensis and $P$. oulorum, also require haemin for growth or are usually cultivated in the presence of haemin (Holdeman et al., 1984; Shah et al., 1985). Growth of strain $\mathrm{KB}^{\mathrm{T}}$ was also strongly stimulated by the addition of haemin to the medium. Since the haemin requirement of Prevotella species has often been considered in relation to haem or haemoglobin derived from host animals (Leung \& Folk, 2002), it is of interest that haemin also stimulates the growth of a bacterium isolated from a plant residue sample in flooded soil. Although cells of Prevotella or Bacteroides species are often known to be pleomorphic depending on the culture conditions (Holdeman et al., 1984), the morphology of long filamentous rods cultivated in the absence of haemin seems to be a unique feature of strain $\mathrm{KB}^{\mathrm{T}}$ together with the slightly acidophilic property.

The ranges of substrate utilization of the related species $P$. bivia and $P$. oulorum are relatively restricted and these species are not able to utilize carbohydrates such as arabinose, xylose and cellobiose. Furthermore, utilization of polymers such as xylan, pectin and CMC is never reported. Strain $\mathrm{KB}^{\mathrm{T}}$ is able to use various carbohydrates, including polymers (xylan, pectin, CMC and starch) and disaccharides (e.g. cellobiose, trehalose and sucrose), as well as hexoses and pentoses, including arabinose and xylose. $P$. albensis, isolated from rumen, utilizes a relatively wide range of carbohydrates, including xylose and xylan, which were

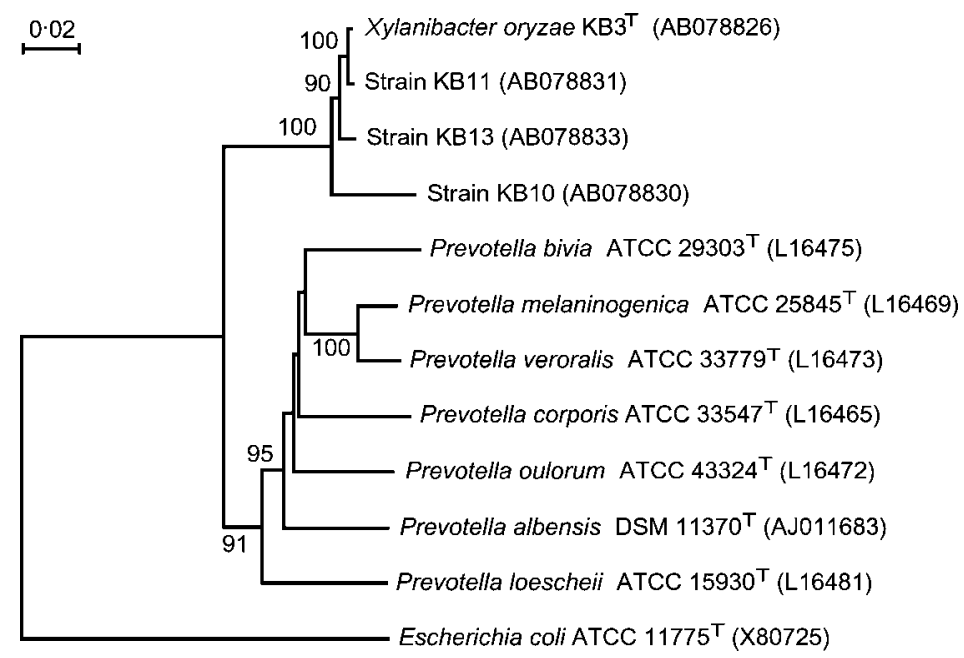

Fig. 2. Neighbour-joining tree showing the phylogenetic relationship of strain $\mathrm{KB}^{\top}$ and related species in the phylum Bacteroidetes based on 16S rRNA gene sequences. Bootstrap values (expressed as percentages of 1000 replications) above $50 \%$ are shown at branch nodes. The sequence of Escherichia coli ATCC $11775^{\top}$, which belongs to the Gammaproteobacteria (Garrity \& Holt, 2001), was used as the outgroup. Bar, $2 \%$ estimated difference in nucleotide sequence position. 
Table 2. Characteristics that differentiate strain $\mathrm{KB}^{\top}$ from related species

Strains: 1, strain $\mathrm{KB}^{\mathrm{T}}$; 2, Prevotella bivia ATCC $29303^{\mathrm{T}}$ (data from Holdeman et al., 1984); 3, Prevotella albensis DSM $11370^{\mathrm{T}}$ (data from Holdeman et al., 1984; Avgustin et al., 1997; data for major cellular fatty acids and predominant quinones are those of Bacteroides ruminicola subsp. ruminicola from Shah \& Collins, 1980); 4, Prevotella oulorum ATCC 43324 ${ }^{\mathrm{T}}$ (data from Shah et al., 1985). +, Positive; -, negative; ND, no data available; F, formate; A, acetate; P/p, propionate; S, succinate; $\mathrm{m}$, malate; ib, iso-butyrate; iv, iso-valerate. Lower-case letters indicate minor products. Products in parentheses may or may not be detected.

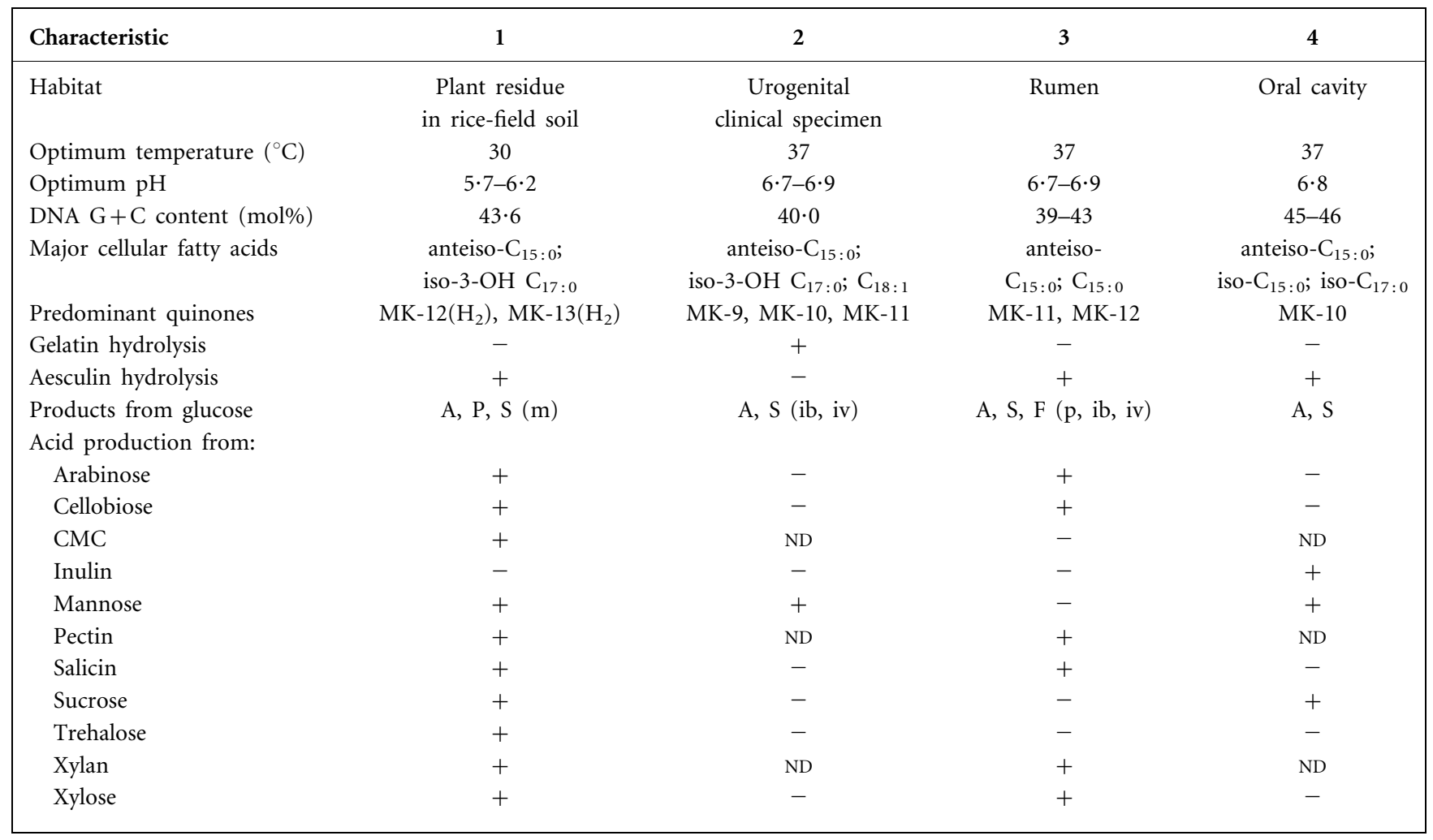

key characteristics used to divide Bacteroides ruminicola into subspecies (B. ruminicola subsp. ruminicola and B. ruminicola subsp. brevis) (Holdeman et al., 1984). P. albensis, established from the former subspecies, is reported to utilize pectin strongly as well as arabinose and cellobiose. Thus, strain $\mathrm{KB} 33^{\mathrm{T}}$ has characteristics common to Prevotella species isolated from rumen as regards the utilization of polymers, however, the range of carbohydrate utilization of strain $\mathrm{KB}^{\mathrm{T}}$ is different from that of $P$. albensis (e.g. mannose, sucrose, trehalose and CMC) (Table 1).

$P$. bivia and $P$. oulorum produce acetate and succinate as major acids from glucose and production of propionate has never been reported. For $P$. albensis, the major acids from glucose are succinate, acetate and formate. Propionate is not recognized as a major acid (Holdeman et al., 1984; Shah et al., 1985). Strain $\mathrm{KB}^{\mathrm{T}}$ produced a substantial amount of propionate from xylan, irrespective of the presence of haemin. In the presence of the B-vitamin mixture, propionate was usually the major end product from the substrates tested. Since the vitamin mixture could be completely replaced by cyanocobalamin, strain $\mathrm{KB}^{\mathrm{T}}$ is considered to be a propionate-producing bacterium depending on the supply of exogenous cobalamin. A propionate-producing bacterium, Propionicimonas paludicola, which requires cobalamin for growth and propionate production also has been isolated from rice-plant residue samples from the same rice-field (Akasaka et al., 2003b). The requirement for cobalamin for the production of propionate seems to be a rather common physiological characteristic of anaerobic bacteria living in anoxic environments such as flooded soil.

The $\mathrm{G}+\mathrm{C}$ content of the genomic DNA of strain $\mathrm{KB}^{\mathrm{T}}$ $(43.6 \mathrm{~mol} \%)$ is similar to those of related species (Table 2) (Holdeman et al., 1984; Shah et al., 1985). It has been reported that the major CFAs of species in the genera Bacteroides and Prevotella are anteiso- $\mathrm{C}_{15: 0}$, iso- $\mathrm{C}_{15: 0}$, iso3-OH $\mathrm{C}_{17: 0}$ and $\mathrm{C}_{16: 0}$ (Miyagawa et al., 1979; Moore et al., 1994). Although iso- $C_{15: 0}$ and $C_{16: 0}$ were only minor components of the CFAs for strain $\mathrm{KB} 3^{\mathrm{T}}$, the overall pattern of the CFA content with anteiso- $\mathrm{C}_{15: 0}$ and iso-3-OH $\mathrm{C}_{17: 0}$ as major components seems to be within the variation of those reported for species of the genera Bacteroides and Prevotella. However, since the closest relative of strain $\mathrm{KB}^{\mathrm{T}}$, P. bivia, has unsaturated fatty acid $\left(\mathrm{C}_{18: 1}\right)$ as the dominant CFA $(18.9 \%)$ together with anteiso- $\mathrm{C}_{15: 0}(16.9 \%)$ and iso3-OH C $17: 0(17 \cdot 9 \%)$ as major CFAs (Sakamoto et al., 2004), 
the CFA composition of strain $\mathrm{KB} 3^{\mathrm{T}}$ is rather different from that of its closest relative.

P. bivia possesses menaquinones MK-9 (5\%), MK-10 (70\%) and MK-11 (23\%) (Sakamoto et al., 2005) and $P$. oulorum has MK-10 (Shah et al., 1985). Prevotella species from rumen usually have menaquinone MK-11 as one of predominant menaquinones (Shah \& Collins, 1980). Since strain $\mathrm{KB} 3{ }^{\mathrm{T}}$ possesses menaquinones $\mathrm{MK}-12\left(\mathrm{H}_{2}\right)$ and $\mathrm{MK}$ $13\left(\mathrm{H}_{2}\right)$, the menaquinone composition is rather different from those of related Prevotella species.

Strain $\mathrm{KB}^{\mathrm{T}}$ was isolated from rice-plant residue (plant stubble and roots) together with some very closely related strains [strains KB10 (=JCM 13649=DSM 17971), KB11 and KB13; GenBank 16S rRNA gene sequence accession numbers $\mathrm{AB} 07880, \mathrm{AB} 078831$ and $\mathrm{AB} 078833$, respectively] (Akasaka et al., 2003a) (Fig. 2). The population density of this bacterial group, determined by the dilution-colonycounting method, was enumerated at the order of $10^{9}$ c.f.u. $\mathrm{g}^{-1}$ dry weight. Thus, this bacterial group seems to be one of the dominant groups living in plant residues in rice-field soil and has functions in decomposing plant biomass, such as hemicellulose and pectin, as well as substrates derived from the decomposition of these components, including solubilized cellulose.

Strain $\mathrm{KB}^{\mathrm{T}}$ is phylogenetically distant from the closest related species that are all derived from mammals and has characteristics that are distinct from these related species. Analyses using various environmental clones from samples isolated from sources other than animals have shown that bacterial groups belonging to the phylum Bacteroidetes are frequently detected as one of the predominant groups and most of them have never been cultivated (Lydell et al., 2004; Chouari et al., 2005). Strain $\mathrm{KB}^{\mathrm{T}}$ may represent such an uncultured bacterial group taking a role in anaerobic decomposition of plant biomass.

On the basis of the comprehensive analyses of the phenotypic, chemotaxonomic and phylogenetic characteristics described above and its ecological origin, we propose a novel genus, Xylanibacter gen. nov., with strain $\mathrm{KB}^{\mathrm{T}}{ }^{\mathrm{T}}$ representing the type strain of the type species, Xylanibacter oryzae sp. nov.

\section{Description of Xylanibacter gen. nov.}

Xylanibacter (Xy.la.ni.bac'ter. N.L. n. xylanum xylan; N.L. masc. n. bacter a rod; N.L. masc. n. Xylanibacter rod decomposing xylan).

Cells are Gram-negative, non-spore-forming, non-motile, short to filamentous rods. Strictly anaerobic. Chemoorganotroph. Optimum growth temperature is $30^{\circ} \mathrm{C}$. Oxidase, catalase and nitrate-reducing activities are negative. Utilize various sugars including xylan and produce acetate, propionate and succinate as major fermentation end products. Major cellular fatty acids are anteiso- $\mathrm{C}_{15: 0}$ and
iso-3-OH $\mathrm{C}_{17: 0}$. Major respiratory quinones are $\mathrm{MK}-12\left(\mathrm{H}_{2}\right)$ and MK-13( $\left.\mathrm{H}_{2}\right)$. The type species is Xylanibacter oryzae.

\section{Description of Xylanibacter oryzae sp. nov.}

Xylanibacter oryzae (o'ry.zae. L. fem. n. oryza rice and the genus name of rice; L. gen. n. oryzae from/of rice or rice plants, referring to rice-plant residue from which the strain was isolated).

Has the following properties in addition to those given for the genus. Haemin significantly stimulates growth. In the presence of B-vitamin mixture as well as haemin, acetate, propionate and succinate are produced as major fermentation products. Slightly acidophilic and grows with an optimum $\mathrm{pH}$ of $5 \cdot 7-6 \cdot 2$ ( $\mathrm{pH}$ range, $4 \cdot 7-7 \cdot 3$ ). Growth temperature range is $15-35^{\circ} \mathrm{C}$ with the optimum at $30^{\circ} \mathrm{C}$. Growth at $37^{\circ} \mathrm{C}$ is significantly delayed. $\mathrm{NaCl}$ concentration range for growth is $0-0.5 \%(\mathrm{w} / \mathrm{v})$ in PYG medium containing haemin and B-vitamin mixture. Utilizes arabinose, ribose, xylose, fructose, galactose, glucose, mannose, rhamnose, cellobiose, lactose, maltose, sucrose, trehalose, CMC, soluble starch, xylan, pectin, salicin and pyruvate as growth substrates. Acids are produced from these substrates, but gas is not. Does not use sorbose, melezitose, cellulose powder, filter paper, inulin, glycerol, inositol, mannitol, fumarate, lactate, malate or succinate. Aesculin is hydrolysed, but gelatin is not. Urease is negative. Hydrogen sulfide and indole are not produced. Does not grow in the presence of bile salts. The genomic DNA G $+\mathrm{C}$ content is $43.6 \mathrm{~mol} \%$.

The type strain, $\mathrm{KB}^{\mathrm{T}}\left(=\mathrm{JCM} 13648^{\mathrm{T}}=\mathrm{DSM} 17970^{\mathrm{T}}\right)$, was isolated from stubble and roots of rice-plant residue in anoxic rice-field soil in Japan.

\section{Acknowledgements}

We are grateful to Yoshimi Ohtaki for her technical assistance in physiological examinations of the strain. This work was partly supported by a Grant-in-Aid for Scientific Research (no. 16580271) from the Japan Society for Promotion of Science and also by the Project for Development of Technology for Analysing and Controlling the Mechanism of Biodegrading and Processing supported by the New Energy and Industrial Technology Development of Organization (NEDO).

\section{References}

Akasaka, H., Izawa, T., Ueki, K. \& Ueki, A. (2003a). Phylogeny of numerically abundant culturable anaerobic bacteria associated with degradation of rice plant residue in Japanese paddy field soil. FEMS Microbiol Ecol 43, 149-161.

Akasaka, H., Ueki, A., Hanada, S., Kamagata, Y. \& Ueki, K. (2003b). Propionicimonas paludicola gen. nov., sp. nov., a novel facultatively anaerobic, Gram-positive, propionate-producing bacterium isolated from plant residue in irrigated rice-field soil. Int J Syst Evol Microbiol 53, 1991-1998.

Akasaka, H., Ueki, K. \& Ueki, A. (2004). Effects of plant residue extract and cobalamin on growth and propionate production of 
Propionicimonas paludicola isolated from plant residue in irrigated rice field soil. Microbes Environ 19, 112-119.

Altschul, S. F., Madden, T. L., Schäffer, A. A., Zhang, J., Zhang, Z., Miller, W. \& Lipman, D. J. (1997). Gapped BLAST and PSI-BLAST: a new generation of protein database search programs. Nucleic Acids Res 25, 3389-3402.

Avgustin, G., Wallace, R. J. \& Flint, H. (1997). Phenotypic diversity among ruminal isolates of Prevotella ruminicola: proposal of Prevotella brevis sp. nov., Prevotella bryantii sp. nov., and Prevotella albensis sp. nov. and redefinition of Prevotella ruminicola. Int J Syst Bacteriol 47, 284-288.

Boone, R. D. (2000). Biological formation and consumption of methane. In Atmospheric Methane, pp. 42-62. Edited by M. A. K. Khalil. Berlin: Springer.

Chouari, R., Le Paslier, D., Daegelen, P., Ginestet, P., Weissenbach, J. \& Sghir, A. (2005). Novel predominant archaeal and bacterial groups revealed by molecular analysis of an anaerobic sludge digester. Environ Microbiol 7, 1104-1115.

Garrity, G. M. \& Holt, J. G. (2001). The road map to the Manual. In Bergey's Manual of Systematic Bacteriology, 2nd edn, vol. 1, pp. 119-166. Edited by D. R. Boone, R. W. Castenholz \& G. M. Garrity. New York: Springer.

Holdeman, L. V. \& Johnson, J. L. (1977). Bacteroides disiens sp. nov. and Bacteroides bivius sp. nov. from human clinical infections. Int J Syst Bacteriol 27, 337-345.

Holdeman, L. V., Cato, E. P. \& Moore, W. E. C. (1977). Anaerobe Laboratory Manual, 4th edn. Blacksburg, VA: Virginia Polytechnic Institute and State University.

Holdeman, L. V., Kelly, R. W. \& Moore, W. E. C. (1984). Genus I. Bacteroides Castellani and Chalmers 1919, 959. In Bergey's Manual of Systematic Bacteriology, vol. 1, pp. 604-631. Edited by N. R. Krieg \& J. G. Holt. Baltimore: Williams \& Wilkins.

Hungate, R. E. (1966). The Rumen and Its Microbes. New York: Academic Press.

Kamagata, Y. \& Mikami, E. (1991). Isolation and characterization of a novel thermophilic Methanosaeta strain. Int J Syst Bacteriol 41, 191-196.

Khalil, M. A. K. (2000). Atmospheric Methane. Berlin: Springer.

Komagata, K. \& Suzuki, K. (1987). Lipid and cell-wall analysis in bacterial systematics. Methods Microbiol 19, 161-207.

Lawson, P. A., Falsen, E., Inganas, E., Weyant, R. S. \& Collins, M. D. (2002). Dysgonomonas mossii sp. nov., from human sources. Syst Appl Microbiol 25, 194-197.

Leung, K.-P. \& Folk, S. P. (2002). Effects of porphyrins and inorganic iron on the growth of Prevotella intermedia. FEMS Microbiol Lett 209, 15-29.

Lydell, C., Dowell, L., Sikaroodi, M., Gillevet, P. \& Emerson, D. (2004). A population survey of members of the phylum Bacteroidetes isolated from salt marsh sediments along the east coast of the United States. Microb Ecol 48, 263-273.

Miller, L. T. (1982). Single derivatization method for routine analysis of bacterial whole-cell fatty acid methyl esters, including hydroxyl acids. J Clin Microbiol 16, 584-586.

Miyagawa, E., Azuma, R. \& Suto, E. (1979). Cellular fatty acid composition in Gram-negative obligately anaerobic rods. J Gen Appl Microbiol 25, 41-51.

Moore, L. V. H., Bourne, D. M. \& Moore, W. E. C. (1994). Comparative distribution and taxonomic value of cellular fatty acids in thirty-three genera of anaerobic Gram-negative bacilli. Int J Syst Bacteriol 44, 338-347.

Paster, B. J., Dewhirst, F. E., Olsen, I. \& Fraser, G. J. (1994). Phylogeny of Bacteroides, Prevotella, and Porphyromonas spp. and related bacteria. J Bacteriol 176, 725-732.

Saitou, N. \& Nei, M. (1987). The neighbor-joining method: a new method for reconstructing phylogenetic trees. Mol Biol Evol 4, 406-425.

Sakamoto, M., Suzuki, M., Huang, Y., Umeda, M., Ishikawa, I. \& Benno, Y. (2004). Prevotella shahii sp. nov. and Prevotella salivae isolated from the human oral cavity. Int J Syst Evol Microbiol 54, 877-883.

Sakamoto, M., Huang, Y., Umeda, M., Ishikawa, I. \& Benno, Y. (2005). Prevotella multiformis sp. nov., isolated form human subgingival plaque. Int J Syst Evol Microbiol 55, 815-819.

Satoh, A., Watanabe, M., Ueki, A. \& Ueki, K. (2002). Physiological properties and phylogenetic affiliations of anaerobic bacteria isolated from roots of rice plants cultivated on a paddy field. Anaerobe 8, 233-246.

Seiler, W., Holzapfel-Pschorn, A., Conrad, R. \& Scharffe, D. (1984). Methane emission from rice paddies. J Atmos Chem 1, 241-268.

Shah, H. N. \& Collins, D. M. (1980). Fatty acid and isoprenoid quinone composition in the classification of Bacteroides melaninogenicus and related taxa. J Appl Bacteriol 48, 75-87.

Shah, H. N. \& Collins, D. M. (1989). Proposal to restrict the genus Bacteroides (Castellani and Chalmers) to Bacteroides fragilis and closely related species. Int J Syst Bacteriol 39, 85-87.

Shah, H. N. \& Collins, D. M. (1990). Prevotella, a new genus to include Bacteroides melaninogenicus and related species formerly classified in the genus Bacteroides. Int J Syst Bacteriol 40, 205-208.

Shah, H. N., Collins, D. M., Watabe, J. \& Mitsuoka, T. (1985). Bacteroides oulorum sp. nov., a non-pigmented saccharolytic species from the oral cavity. Int J Syst Bacteriol 35, 193-197.

Takai, Y. (1970). The mechanism of methane fermentation in flooded paddy soil. Soil Sci Plant Nutr 6, 238-244.

Thompson, J. D., Higgins, D. G. \& Gibson, T. J. (1994). CLUSTAL W: improving the sensitivity of progressive multiple sequence alignment through sequence weighting, position-specific gap penalties and weight matrix choice. Nucleic Acids Res 22, 4673-4680.

Ueki, A. \& Suto, T. (1979). Cellular fatty acid composition of sulfatereducing bacteria. J Gen Appl Microbiol 25, 185-196.

Ueki, A., Matsuda, K. \& Ohtsuki, C. (1986). Sulfate reduction in the anaerobic digestion of animal waste. J Gen Appl Microbiol 32, 111-123.

Ueki, A., Kainuma, Y., Fujii, H. \& Ueki, K. (2000). Seasonal variations in vertical distribution of methanogenic activity and $\mathrm{Fe}$ (II) content and relationship between them in wetland rice field soil. Soil Sci Plant Nutr 46, 401-415.

Ueki, A., Akasaka, H., Suzuki, D. \& Ueki, K. (2006). Paludibacter propionicigenes gen. nov., sp. nov., a novel strictly anaerobic, Gramnegative, propionate-producing bacterium isolated from plant residue in irrigated rice-field soil in Japan. Int $J$ Syst Evol Microbiol 56, 39-44.

Wassmann, R., Neue, H. U., Lantin, R. S., Buendia, L. V. \& Rennenberg, H. (2000a). Characterization of methane emissions from rice fields in Asia. I. Comparison among field sites in five countries. Nutr Cycl Agroecosys 58, 1-12.

Wassmann, R., Neue, H. U., Lantin, R. S., Makarim, K., Chareonsilp, N., Buendia, L. V. \& Rennenberg, H. (2000b). Characterization of methane emissions from rice fields in Asia. II. Differences among irrigated, rainfed, and deepwater rice. Nutr Cycl Agroecosys 58, 13-22. 